\title{
Prevalence of Urogenital Mycoplasmas Among Men with NGU in Upper Silesia, Poland. Preliminary Study
}

\author{
ALICJA EKIEL ${ }^{1}$, MAŁGORZATA APTEKORZ ${ }^{1}$, PIOTR KŁUCIŃSKI는, DOMINIKA SMOLEC ${ }^{1}$, \\ BARBARA WIECHUŁA ${ }^{1}$, JAROSŁAW JÓŹWIAK ${ }^{2}$ and GAYANE MARTIROSIAN ${ }^{1,2 *}$
}

\begin{abstract}
${ }^{1}$ Department of Medical Microbiology, School of Medicine in Katowice, Medical University of Silesia, Katowice, Poland
${ }^{2}$ Department of Histology and Embryology Warsaw Medical University, Warsaw, Poland
\end{abstract}

Submitted 17 September 2013, revised 28 September 2013, accepted 3 September 2015

\begin{abstract}
The prevalence of urogenital mycoplasmas in men with NGU in Upper Silesia (Poland) was studied. Mycoplasmas were detected in 36.7\% men (Ureaplasma parvum and Mycoplasma genitalium were found in 30\% and $16.7 \%$ respectively). Urealyticum urealyticum was not detected. We suggest including M. genitalium in the diagnostic scheme for nongonococcal urethritis (NGU).
\end{abstract}

Key words: Mycoplasma genitalium, nongonococcal urethritis, urogenital mycoplasmas

The importance of ureaplasmas as a cause of nongonococcal urethritis (NGU) is discussed. The topic of this discussion has taken on a new meaning since 1999, when Kong et al. (1999) divided the genera Ureaplasma into two new species Ureaplasma parvum and Ureaplasma urealyticum. Mycoplasma genitalium was being isolated from urethra of men with NGU until 1980, but only recently was confirmed as an important etiology of NGU in men (Workowski and Berman, 2010). In Poland detection of urogenital mycoplasmas is not a part of routine diagnostic procedure. Few published papers cover mainly pregnant women and newborns.

The aim of this study was to evaluate the prevalence of M.genitalium and Ureaplasmas in men with NGU, taking into account the diversity of the species (U.parvum and $U$. urealyticum). According to our knowledge, this is the first such study in Poland.

Thirty male patients aged $30-55$ years (mean age $38 \pm 5.68$ years) diagnosed with NGU (clinical symptoms, microscopic preparation, after excluding Chlamydia trachomatis) were directed for detection of urogenital mycoplasmas. All men gave informed consent for this study. Patients were advised of the need to maintain sexual abstinence for 3-4 days and were obliged to come to testing at minimum $4 \mathrm{~h}$ after the last voiding. This study was approved by the Bioethical Committee of Medical University of Silesia.

Isolation of mycoplasmal DNA was performed from a pellet obtained from culture in Mycoplasma IST 2
(bioMérieux, Marcy I'Etoile, France). Identification of U. parvum, U. urealyticum and intraspecific diversity of $U$. parvum was done using species-specific primers according to Kong et al. (2000). Detection of M. genitalium was conducted using primers for adhesin genes: MgPa-1 - MgPa-3 and for 16S rRNA gene MG16-45F - MG16-447R; MG16-1204F - MG16-1301R primers were designed according to Jensen et al. $(1991 ; 2003)$.

In 9/30 (30\%) samples urogenital mycoplasmas were detected with Mycoplasma IST 2 test. PCR amplification confirmed the presence of mycoplasmas in all 9 cases and did not increase the number of positive results for ureaplasmas. However, detection of M. genitalium DNA by PCR increased the number of positive results for urogenital mycoplasmas from 9 cases to 11 (36.7\%). Co-occurrence of two different species of urogenital mycoplasmas was shown in the majority of samples (Table I). Interestingly, species identification

Table I

Occurrence of urogenital mycoplasmas in the study group $(n=30)$.

\begin{tabular}{|l|c|}
\hline & No (\%) \\
\hline M.genitalium & $\mathbf{2}(6.7)$ \\
\hline U.parvum + M. genitalium & $\mathbf{3}(10)$ \\
\hline U.parvum + M. hominis & $\mathbf{2 ( 6 . 7 )}$ \\
\hline U.parvum & $\mathbf{4}(13.3)$ \\
\hline Total & $\mathbf{1 1}(36.7)$ \\
\hline
\end{tabular}

\footnotetext{
* Corresponding author: A. Ekiel, Department of Medical Microbiology, School of Medicine in Katowice, Medical University of Silesia, Katowice, Poland; e-mail: aekiel@sum.edu.pl
} 
Table II

Results of M. genitalium DNA detection by PCR with selected primers in men with NGU $(n=30)$.

\begin{tabular}{|c|c|c|c|c|}
\hline \multirow{2}{*}{$\begin{array}{c}\text { Number } \\
\text { of studied } \\
\text { cases }\end{array}$} & \multicolumn{3}{|c|}{ Primers } & \multirow{2}{*}{$\begin{array}{c}\text { Final } \\
\text { interpretation }\end{array}$} \\
\cline { 2 - 5 } & Mg16-45F+Mg16-447R & Mg16-1204F+MG16-1301R & MgPa-1+MgPa-3 & Positive \\
\hline 1 & Positive & Positive & Positive & Positive \\
\hline 4 & Negative & Positive & Posititve & Pegative \\
\hline 4 & Negative & Negative & Negative & Negative \\
\hline 21 & Negative & Negative & & \\
\hline
\end{tabular}

revealed the presence of $U$.parvum in all cases, in contrast to U. urealyticum strains, which were not detected. Domination of U.parvum in our study group was concordant with others (Tang et al., 2011; Vancutsem et al., 2011). Several studies have shown that U. urealyticum was significantly more common in men with NGU (Maeda et al., 2004; Manhart et al., 2013). Among isolated mycoplasmas U. parvum was detected significantly more often than M. hominis ( $\mathrm{p}=0.0453)$. However domination of $U$. parvum in comparison to M. genitalium was not significant $(\mathrm{p}=0.3598)$. Although the presence of M. genitalium DNA by PCR using primers for adhesin genes $\mathrm{MgPa}$ was shown in specimens from $9(30 \%)$ men with NGU, primers for 16S rRNA gene confirmed the presence of M. genitalium in only 5 samples (16.7\%, Table II). The rule that double-positive amplicon for adhesin gene with primers $\mathrm{MgPa}-1 /$ $\mathrm{MgPa}-3$ and double-positive for one of the primers for 16S rRNA gene could be considered as positive was used in the interpretation of the obtained results (Tabele II). The decrease in the number of positive cases from $9 / 30$ to 5/30 in the study group of men was not significant. According to other authors, confirmation of positive results through repetition or the use of different primers are required (Manhart et al., 2003). Gaydos et al. (2009) recognized a patient's infection only when positive results with primers for both $\mathrm{MgPa}$ and $16 \mathrm{~S}$ rRNA genes were achieved. Among the analysed specimens from 719 women (Manhart et al., 2003) 51 were doublepositive using primer pairs for $\mathrm{MgPa}$ genes. Furthermore, only $45(88.2 \%)$ of 51 double-positive results were confirmed using PCR for 16S rRNA gene. At the same time, for none of 49 selected MgPa PCR-negative specimens, positive results with primers for $16 \mathrm{~S}$ rRNA gene were demonstrated. Edberg et al. (2008) achieved higher sensitivity by real-time PCR for MgPa gene, compared to conventional PCR for 16S rRNA gene. Moreover, the authors demonstrated much higher sensitivity in contrary to real-time PCR for $16 \mathrm{~S}$ rRNA gene.

The urogenital mycoplasmas are recognized in a large percentage of men with NGU. However, in order to properly interpret the presence and role of urogenital mycoplasmas in the etiology of infection, the result of the test should be complete. The outcome has to contain both: detection of M. genitalium DNA and identification of ureaplasmas to U.parvum and U. urealyticum. Japanese authors identified M. genitalium, U. urealyticum and U.parvum in men with NGU with a frequency of $17 \%, 16.3 \%$ and $7.8 \%$ respectively; among the patients with non-chlamydial NGU $-23.8 \%, 18.8 \%$ and $8.8 \%$ respectively (Maeda et al., 2004). In a study from Denmark, the prevalence of M. genitalium infection was $2.3 \%$ and $1.1 \%$ respectively in 731 men and 921 women aged 21-23 years, not seeking medical assistance (Andersen et al., 2007). Detection rate of M. genitalium DNA in urine from asymptomatic healthy young Japanese men was only $1 \%$ (Takahashi et al., 2006).

The absence of $U$. urealyticum in our specimens was probably due first of all to small size of the study group and secondly, the low frequency of isolation of U. urealyticum in the Polish population, demonstrated previously in a group of women (Ekiel et al., 2009). Similar results of low percentage of U. urealyticum were indicated in other countries (Tang et al., 2011; Vancutsem et al., 2011). A limitation of our study was the absence of a control group due to the fact that taking urethral swabs is invasive and poorly accepted by men.

The usefulness of the first - void urine (FVU) in molecular biology studies was shown by other authors. Thanks to this, availability of research on urogenital mycoplasmas certainly will increase (Takahashi et al., 2006; Wroblewski et al., 2006).

M. genitalium is now an important and established cause of approximately 9-25\% cases of NGU (Workowski and Berman, 2010; Manhart et al., 2013). In spite of that fact that our study group was limited, $16.7 \%$ positive M. genitalium cases confirmed the role of this microorganism as an important causative agent of NGU. Furthermore, our study points to the requirement of including M.genitalium in the diagnostic scheme for patients with non-chlamydial NGUs.

\section{Literature}

Andersen B., I. Sokolowski, L. Østergaard, J. Kjølseth Møller, F. Olesen and J.S. Jensen. 2007. Mycoplasma genitalium: prevalence and behavioural risk factors in the general population. Sex Transm. Infect. 83: 237-241. 
Edberg A., M. Jurstrand, E. Johansson, E. Wikander, A. Höög, T. Ahlqvist, L. Falk, J.S. Jensen and H. Fredlund. 2008. A comparative study of three different PCR assays for detection of Mycoplasma genitalium in urogenital specimens from men and women. J. Med. Microbiol. 57: 304-309.

Ekiel A.M., B. Pietrzak, P. Kamiński, H. Dolezych, J. Jóźwiak and G. Martirosian. 2009. Prevalence of urogenital mycoplasmas and ureaplasmas in women after kidney transplantation. Transplantation 87: 848-851.

Gaydos C., N.E. Maldeis, A. Hardick, J. Hardick and T.C. Quinn. 2009. Mycoplasma genitalium as a contributor to the multiple etiologies of cervicitis in women attending sexually transmitted disease clinics. Sex Transm. Dis. 36: 598-606.

Jensen J.S., S.A. Uldum, J. Søndergård-Andersen, J. Vuust and K. Lind. 1991. Polymerase chain reaction for detection of Mycoplasma genitalium in clinical samples. J. Clin. Microbiol. 29: 46-50. Jensen J.S., M.B. Borre and B. Dohn. 2003. Detection of Mycoplasma genitalium by PCR amplification of the 16S rRNA gene. J. Clin. Microbiol. 41: 261-266.

Kong F., G. James, Z. Ma, S. Gordon, W. Bin and G.L. Gilbert. 1999. Phylogenetic analysis of Ureaplasma urealyticum - support for the establishment of a new species, Ureaplasma parvum. Int. J. Syst. Bacteriol. 49: 1879-1889.

Kong F., Z. Ma, G. James, S. Gordon and G.L. Gilbert. 2000. Species identification and subtyping of Ureaplasma parvum and Ureaplasma urealyticum using PCR-based assays. J. Clin. Microbiol. 38 : 1175-1179.

Maeda S., T. Deguchi, H. Ishiko, T. Matsumoto, S. Naito, H. Kumon, T. Tsukamoto, S. Onodera and S. Kamidono. 2004. Detection of Mycoplasma genitalium, Mycoplasma hominis, Ureaplasma parvum (biovar 1) and Ureaplasma urealyticum (biovar 2) in patients with non-gonococcal urethritis using polymerase chain reaction-microtiter plate hybridization. Int. J. Urol. 11: 750-754.

Manhart L.E., C.W. Critchlow, K.K. Holmes, S.M. Dutro, D.A. Eschenbach, C.E. Stevens and P.A. Totten. 2003. Mucopurulent cervicitis and Mycoplasma genitalium. J. Infect. Dis. 187: 650-657. Manhart L.E., C.W. Gillespie, M.S. Lowens, C.M. Khosropour, D.V. Colombara, M.R. Golden, N.R. Hakhu, K.K. Thomas, J.P. Hughes, N.L. Jensen and others. 2013. Standard treatment regimens for nongonococcal urethritis have similar but declining cure rates: a randomized controlled trial. Clin. Infect. Dis. 56: 934-942.

Takahashi S., K. Takeyama, S. Miyamoto, K. Ichihara, T. Maeda, Y. Kunishima, M. Matsukawa and T. Tsukamoto. 2006. Detection of Mycoplasma genitalium, Mycoplasma hominis, Ureaplasma urealyticum, and Ureaplasma parvum DNAs in urine from asymptomatic healthy young Japanese men. J. Infect. Chemother. 12: 269-271.

Tang J., L. Zhou, X. Liu, C. Zhang, Y. Zhao and Y. Wang. 2011. Novel multiplex real-time PCR system using the SNP technology for the simultaneous diagnosis of Chlamydia trachomatis, Ureaplasma parvum and Ureaplasma urealyticum and genetic typing of serovars of C. trachomatis and U. parvum in NGU. Mol. Cell Probes. 25: 55-59. Vancutsem E., O. Soetens, M. Breugelmans, W. Foulon and A. Naessens. 2011. Modified real-time PCR for detecting, differentiating, and quantifying Ureaplasma urealyticum and Ureaplasma parvum. J. Mol. Diagn. 13: 206-212.

Workowski K.A. and S. Berman; Centers for Disease Control and Prevention (CDC). 2010. Sexually transmitted diseases treatment guidelines, 2010. MMWR Recomm. Rep. 59: 1-110.

Wroblewski J.K., L.E. Manhart, K.A. Dickey, M.K. Hudspeth and P.A. Totten. 2006. Comparison of transcription-mediated amplification and PCR assay results for various genital specimen types for detection of Mycoplasma genitalium. J. Clin. Microbiol. 44: 3306-3312. 
